\title{
All-Optical Wavelength Conversion Using Mode Switching in an InP Microdisc Laser
}

\begin{tabular}{|r|l|}
\hline Journal: & Electronics Letters \\
\hline Manuscript ID: & Draft \\
\hline Manuscript Type: & Letter \\
\hline Author: & $\mathrm{n}$ /a \\
\hline Lubmitted by the & $\begin{array}{r}\text { Hofrichter, Jens; IBM Research - Zurich } \\
\text { Raz, Oded; COBRA Research Institute, Eindhoven University of } \\
\text { Technology } \\
\text { Liu, Liu; Photonics Research Group, INTEC, Ghent University-IMEC } \\
\text { Morthier, Geert; Photonics Research Group, INTEC, Ghent } \\
\text { University-IMEC } \\
\text { Horst, Folkert; IBM Research - Zurich } \\
\text { Regreny, Philippe; Université de Lyon, Institut des } \\
\text { Nanotechnologies de Lyon INLUMR5270, CNRS } \\
\text { De Vries, Tjibbe; COBRA Research Institute, Eindhoven University } \\
\text { of Technology } \\
\text { Dorren, Harm; COBRA Research Institute, Eindhoven University of } \\
\text { Technology } \\
\text { Offrein, Bert; IBM Research - Zurich }\end{array}$ \\
\hline \hline Keywords: & $\begin{array}{l}\text { SILICON-ON-INSULATOR, SEMICONDUCTOR LASERS, OPTICAL } \\
\text { SIGNAL PROCESSING, INTEGRATED OPTOELECTRONICS }\end{array}$ \\
\hline \hline
\end{tabular}




\section{All-Optical Wavelength Conversion Using Mode Switching in an InP Microdisc Laser}

J. Hofrichter, O. Raz, L. Liu, G. Morthier, F. Horst, P. Regreny, T. De Vries, H.J.S. Dorren and B.J. Offrein

We report on wavelength conversion using an indium phosphide (InP) based microdisc lasers (MDLs) heterogeneously integrated on a silicon-on-insulator waveguide. Several lasing modes are present within the disc cavity, between which wavelength conversion can be performed by mode switching and spectral filtering. For the first time, we demonstrate low-power wavelength up- and down-conversion using one single MDL. Operation with a bit-error rate (BER) below $10^{-9}$ at $2.5 \mathrm{~Gb} / \mathrm{s}$ and operation below the forward-error-correction (FEC) limit of $10^{-3}$ at $10 \mathrm{~Gb} / \mathrm{s}$ are shown without the use of additional seeding beams.

Introduction: Silicon photonics is a promising technology platform, which is expected to deliver the ever more demanding input-output (IO) bandwidth and $1 \mathrm{O}$ density as required in future computing and communication systems. As silicon does not exhibit electrically pumped optical gain, microdisc lasers are interesting candidates for onchip laser sources emitting at around $1550 \mathrm{~nm}$ [1]. Fig. 1a shows such a laser, which is heterogeneously integrated on top of a pre-structured silicon waveguide using the polymer benzocyclobutene (DVS-BCB) as adhesive [1]. Besides being used as laser sources, these devices, in combination with an external filter, have recently been demonstrated to operate as energy efficient all-optical wavelength converters [2, 3]. 
Such functionality is needed, e.g., in on-chip optical networks for routing and for contention-resolution purposes.

When targeting scalable systems, it is desirable to have a single integrated device exhibiting the functions of both wavelength up- and down-conversion depending on the bias conditions. As we will show, MDLs can be operated in such a manner, enabling micron-size, integrated wavelength converters operating at wavelengths around $1550 \mathrm{~nm}$. Their footprint and power consumption are orders of magnitude smaller than those of other wavelength conversion devices, such as silicon waveguides [4], semiconductor optical amplifiers [5], distributed feedback lasers [6], dielectric Bragg reflector lasers [7], Fabry-Pérot lasers [8] and vertical-cavity surfaceemitting lasers [9]. While for MDLs it has recently been shown that wavelength conversion can be performed towards shorter wavelengths [2], no complementary conversion capabilities to shorter wavelengths were demonstrated. Also, the use of a seeding laser, which greatly improves the operation speed [3], should be avoided to lower the system complexity. In this paper, we report on the operation of a single MDL as both an up and down wavelength converter at high bit rates. Operation with a BER below $10^{-9}$ and with a BER below the FEC limit is reported for a $2.5 \mathrm{~Gb} / \mathrm{s}$ and a $10 \mathrm{~Gb} / \mathrm{s}$ bit stream, respectively.

Mode switching by optical injection: The basic concept for employing a disc laser for wavelength conversion by mode switching can be explained using Fig. 1. Under normal operating conditions, the MDL, whose diameter is $7.5 \mu \mathrm{m}$, emits light into a single longitudinal mode (Fig. 1b, left). Single longitudinal mode operation results from the spectral gain dependence and the large wavelength separation of $\sim 30$ nanometers between consecutive longitudinal modes due to the small micron-sized cavity. Injecting light into any of the non-lasing cavity modes of the MDL forces the disc to lase at the injected wavelength. All other longitudinal modes of the MDL 
including the free-running laser mode will be suppressed (see Fig. 1b, right). Upon removing the injected light the MDL reverts to operating at its original free-running lasing mode. The device can be operated as a signal inverting wavelength converter by injecting a data signal at the suppressed lasing mode and centering a band-pass filter at the free-running mode for subsequent detection.

Static Characterization: The characterization was performed on a custom-made setup with manually aligned fiber probes sensing the grating couplers. The threshold current of the device was $\sim 0.25 \mathrm{~mA}$ and the fiber-coupled power exceeded $10 \mu \mathrm{W}$ for bias currents larger than $3 \mathrm{~mA}$. When biasing the $\mathrm{MDL}$ at $I_{\mathrm{LO}}=2.72 \mathrm{~mA}$, the mode at $\sim 1560 \mathrm{~nm}$ becomes dominant. Due to a shift of the gain spectrum and the variation of the refractive index due to Joule heating, the lasing mode at $\sim 1590 \mathrm{~nm}$ becomes dominant for a higher bias current of $I_{H I}=3.53 \mathrm{~mA}$.. Static locking experiments were performed first to quantify the static extinction ratio of the lasing modes. When biasing the device with $I_{\mathrm{LO}}=2.72 \mathrm{~mA}$ and injecting an external continuous-wave light signal at $1590 \mathrm{~nm}$, an extinction of $25 \mathrm{~dB}$ was obtained as shown in Fig. 2 (top). For $I_{\mathrm{HI}}=3.53 \mathrm{~mA}$ and injection at $1560 \mathrm{~nm}$, an extinction ratio of over $13 \mathrm{~dB}$ was achieved as visible in Fig. 2 (bottom). This proves that the MDL can be injection-locked to either of its suppressed side modes, lending the device to wavelength conversion applications as we will show below. The different noise floors in Fig. 2 stem from the unfiltered EDFA's amplified spontaneous emission accompanying the injected beam.

Dynamic Operation: We performed dynamic measurements to investigate the temporal behavior of the conversion process. The sample was mounted on a thermoelectric cooler to stabilize the device temperature at $18^{\circ} \mathrm{C}$. Radio-frequency probes connected the device with a current source for electrical pumping. The light was then 
coupled out of the chip by a grating coupler using a single-mode fiber. The spectra were then taken by an OSA. For the dynamic experiments, a tunable laser was modulated with a $10 \mathrm{~Gb} / \mathrm{s}$ lithium niobate modulator driven by a $12.5 \mathrm{~Gb} / \mathrm{s}$ pattern generator and subsequently amplified. Then, the converted light was coupled out by a circulator and amplified by a second optical fiber amplifier. The ASE of the amplifier was filtered out by a manually tunable filter centered at the wavelength of the freerunning lasing mode to extract the wavelength-converted signal. Finally, the signal was detected in a high-speed photo diode and either attenuated for BER measurements using a $12.5 \mathrm{~Gb} / \mathrm{s}$ BER tester, or detected by a high-speed optical sampling scope. First, the eye diagrams were recorded demonstrating wavelength conversion at $2.5 \mathrm{~Gb} / \mathrm{s}$ in both conversion directions as shown in Fig. 2 (insets). Then, BER measurements were performed to quantify the quality of the wavelength converted signal for a bias current of $I_{\mathrm{HI}}=3.53 \mathrm{~mA}$. For $2.5 \mathrm{~Gb} / \mathrm{s}$ and a non-return-tozero pseudo-random binary sequence (PRBS) length of $2^{31}-1$, operation with a BER of $1 \times 10^{-10}$ was achieved with a power penalty of $8 \mathrm{~dB}$ at an injection power level of $1.5 \mathrm{dBm}$ as shown in Fig. 3. Assuming a coupling loss of $6 \mathrm{~dB}$, the corresponding emitted waveguide power is $60 \mu \mathrm{W}$, while the injected waveguide power is $355 \mu \mathrm{W}$. Although using no seeding beam greatly simplifies the operating condition, the disadvantages are an increased turn-on delay and a random turn-on behavior as the mode has to recover from noise and spontaneous emission explaining the large power penalties. The penalties can be improved by increasing the output power of the device and carefully trading off the extinction ratio. The inset in Fig. 3 displays the eye diagram at the minimal BER. The extinction ratio is $8.4 \mathrm{~dB}$. At a speed of $10 \mathrm{~Gb} / \mathrm{s}$ and with a PRBS length of $2^{7}-1$, a BER of $3 \times 10^{-4}$ could be achieved at a power penalty of $9 \mathrm{~dB}$. This BER is sufficient for applications using forward-error correction (FEC). 
Conclusion: We have demonstrated the wavelength up- and down-conversion in a single MDL heterogeneously integrated on top of an SOI waveguide. To investigate the application in the system context, the wavelength conversion experiments have been performed without seeding. For the first time, it has been shown that a single MDL can perform both up- and down-conversion, enabling large-scale integrated wavelength conversion systems. Static extinction ratios of $25 \mathrm{~dB}$ and $13 \mathrm{~dB}$, respectively, were shown for injection locking to a side mode. Operation at $2.5 \mathrm{~Gb} / \mathrm{s}$ with a BER lower than $1 \times 10^{-9}$ and a dynamic extinction ratio of over $8 \mathrm{~dB}$ were reported. Furthermore, we demonstrated operation at $10 \mathrm{~Gb} / \mathrm{s}$ with a BER lower than $1 \times 10^{-3}$, i.e. below the FEC limit. The demonstrated speed is on the order of the CPU clock speed and thus suitable for network-on-chip applications. 


\section{References}

1 VAN CAMPENHOUT, J., ROJO-ROMEO, P., REGRENY, P., SEASSAL, D., VAN THOURHOUT, D., VERSTUYFT, S., DI CIOCCIO, L., FEDELI, J.-M., LAGAHE, C., and BAETS, R.: 'Electrically pumped InP-based microdisc lasers integrated with a nanophotonic silicon-on-insulator waveguide circuit', Optics Express, 2007, 15, (11), pp. $6744-6749$

2 LIU, L., VAN CAMPENHOUT, J., ROELKENS, G., VAN THOURHOUT, D., ROJOROMEO, P., REgReNY, P., SEASSAL, C., FEDELI, J.-M., and BAETS, R.: 'Ultralow-power all-optical wavelength conversion in a silicon-on-insulator waveguide based on a heterogeneously integrated III-V microdisc laser', Applied Physics Letters, 2008, 93, (6), pp 061107-061107-3

3 RAZ, O., LIU, L., VAN THOURHOUT, D., ROJO-ROMEO, P., FEDELI, J.-M., and DORREN, H.J.S.: 'High speed wavelength conversion in a heterogeneously integrated disc laser over silicon on insulator for network on a chip applications', Proceedings of the 35th European Conference on Optical Communication (ECOC 2009), September 2009, Vienna.

4 XU, Q., ALMEIDA, V. R., and LIPSON, M.: 'Micrometer-scale all-optical wavelength converter on silicon', Optics Letters, 2005, 30, pp 2733-2735

5 LIU, Y., TANGDIONGGA, E., LI, Z.,DE WAARDT, H., KOONEN, A.M.J., KHOE, G. D., SHU, X., BENNION, I., and DORREN, H.J.S.: 'Error-Free 320-Gb/s All-Optical Wavelength Conversion Using a Single Semiconductor Optical Amplifier', IEEE Journal of Lightwave Technology, 2007, 25, (1), pp 103-108 
6 RAZ, O., HERRERA, J., CALABRETTA, N., TANGDIONGGA, E., ANANTATHANASARN, S., NOTZEL, R., and DORREN, H.J.S.: 'Non-inverted multiple wavelength converter at $40 \mathrm{~Gb} / \mathrm{s}$ using $1550 \mathrm{~nm}$ quantum dot SOA; Electronics Letters, 2008, 44, (16), pp 988-989

7 DURHUUS, T., PEDERSEN, R.J.S., MIKKELSEN, B., STUBKJAER, K.E., OBERG, M., and NILSSON, S.: 'Optical wavelength conversion over $18 \mathrm{~nm}$ at 2.5 Gb/s by DBR-Laser', IEEE Photonics Technology Letters, 1993, 5, (1), pp 86-88

8 CHOW, C.W., WONG, C. S., and TSANG, H. K.: 'All-optical NRZ to RZ format and wavelength converter by dual wavelength injection locking', Optics Communications, 2004, 209, pp 329-334

9 ONISHI, Y., NISHIYAMA, N., CANEU, C., KOYAMA, F., and ZAH, C.: 'All-optical inverter based on long-wavelength vertical cavity surface emitting laser', IEEE Journal of Selected Topics in Quantum Electronics, 2005, 11, pp 999-1005 


\section{Acknowledgments:}

This work was supported by the European Union FP7-ICT projects "HISTORIC" and "WADIMOS".

\section{Authors' affiliations:}

J. Hofrichter, F. Horst and B.J. Offrein (IBM Research - Zurich, Säumerstrasse 4, 8803 Rüschlikon, Switzerland)

E-mail: jho@zurich.ibm.com

O. Raz, T. De Vries and H.J.S. Dorren (COBRA Research Institute, Eindhoven University of Technology, Eindhoven, P.O. Box 513, NL-5600 MB, The Netherlands)

L. Liu and G. Morthier (Photonics Research Group, INTEC, Ghent University-IMEC, St-Pietersnieuwstraat 41, 9000 Ghent, Belgium)

P. Regreny (Université de Lyon; Institut des Nanotechnologies de Lyon INLUMR5270, CNRS, Ecole Centrale de Lyon, Ecully, F-69134, France)

L. Liu: Now with the School for Information and Optoelectronic Science and Engineering, South China Normal University, Guangzhou 510000, China 


\section{Figure captions:}

Fig. 1 a) Device structure of an MDL heterogeneously integrated on a silicon-oninsulator waveguide. The InP cavity is mounted on top of a pre-structured silicon nanophotonic waveguide using DVS-BCB as adhesive material and electrically connected using platinum-gold metal pads. b) Principle of mode switching in a disc laser. Left: Free-running (FR) lasing with the predominant wavelength $\lambda_{\mathrm{FR}}$. Right: Light is injected into the side-mode at $\lambda_{\mathrm{INJ}}$ suppressing the free-running mode at $\lambda_{\mathrm{FR}}$.

Fig. 2 Top: Lasing spectrum for $I_{\mathrm{LO}}=2.72 \mathrm{~mA}$ with and without external injection at $1590 \mathrm{~nm}$. Bottom: Lasing spectrum for $I_{\mathrm{HI}}=3.53 \mathrm{~mA}$ with and without external injection at $1560 \mathrm{~nm}$. The insets denote the dynamic operation at $2.5 \mathrm{~Gb} / \mathrm{s}$ at the respective bias currents and injection wavelengths.

Fig. 3 Bit-error rate measurements of the MDL and the back-to-back (B2B) system at a data rate of $2.5 \mathrm{~Gb} / \mathrm{s}$ and $10 \mathrm{~Gb} / \mathrm{s}$. The MDL bias current is $I_{\mathrm{HI}}=3.53 \mathrm{~mA}$. The inset displays the eye diagram obtained for a BER of $10^{-10}$ at $2.5 \mathrm{~Gb} / \mathrm{s}$ 
Figure 1

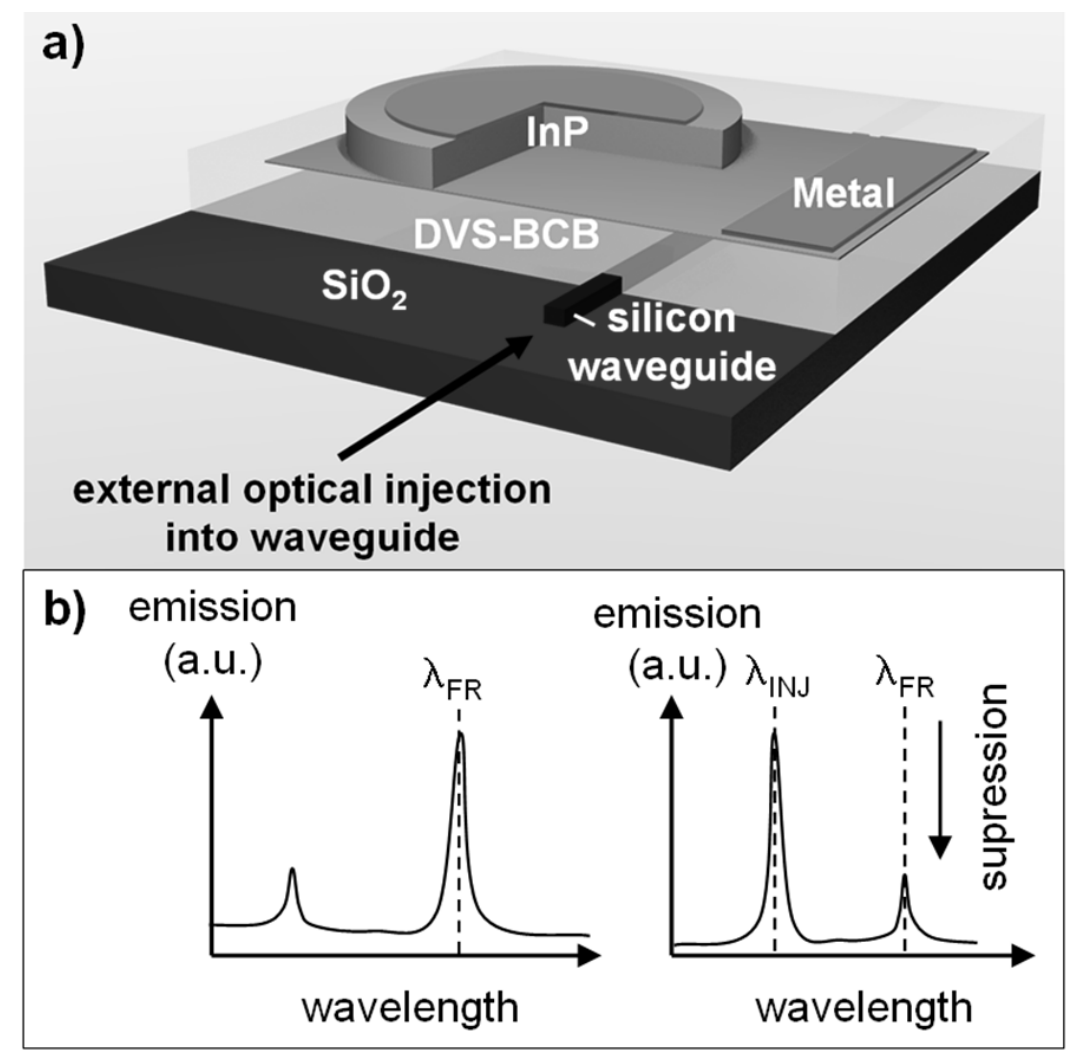


Figure 2

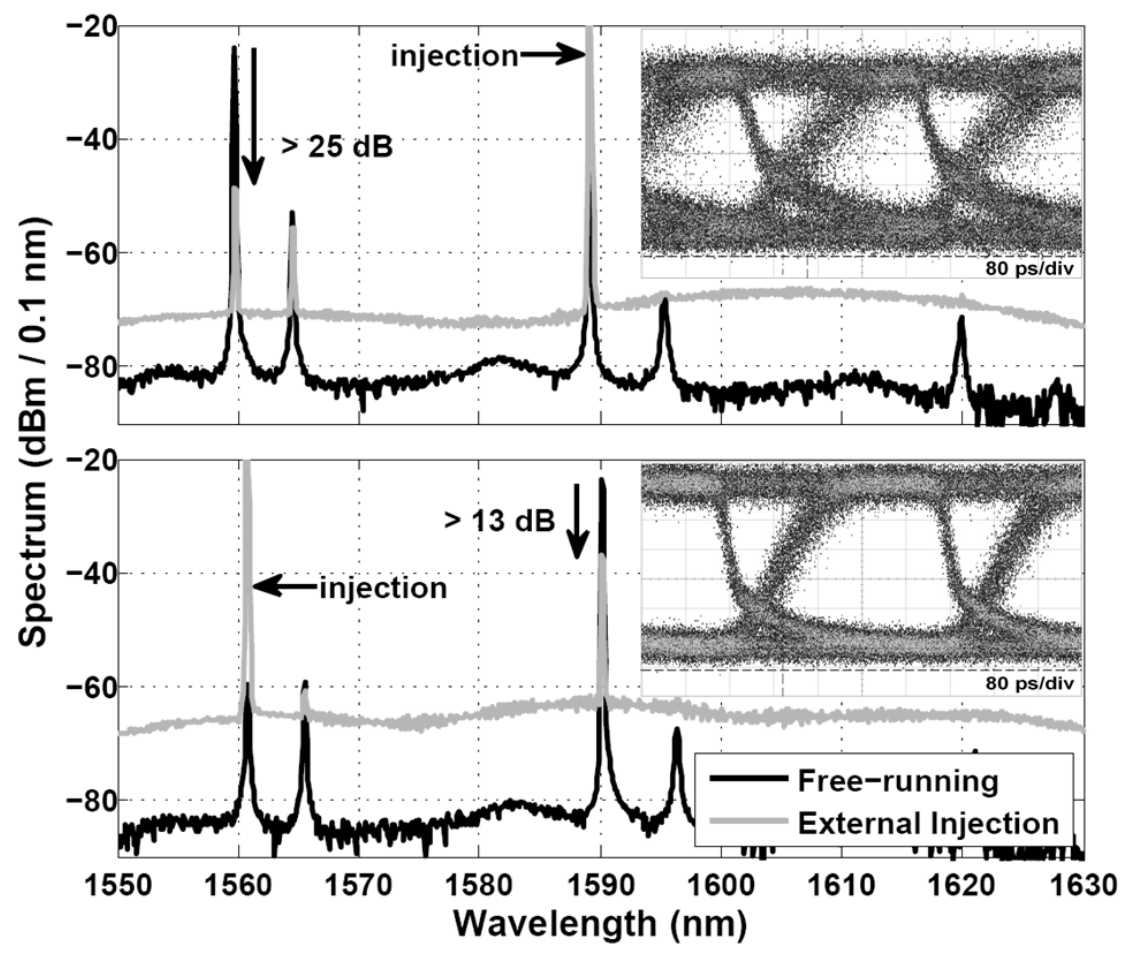


Figure 3

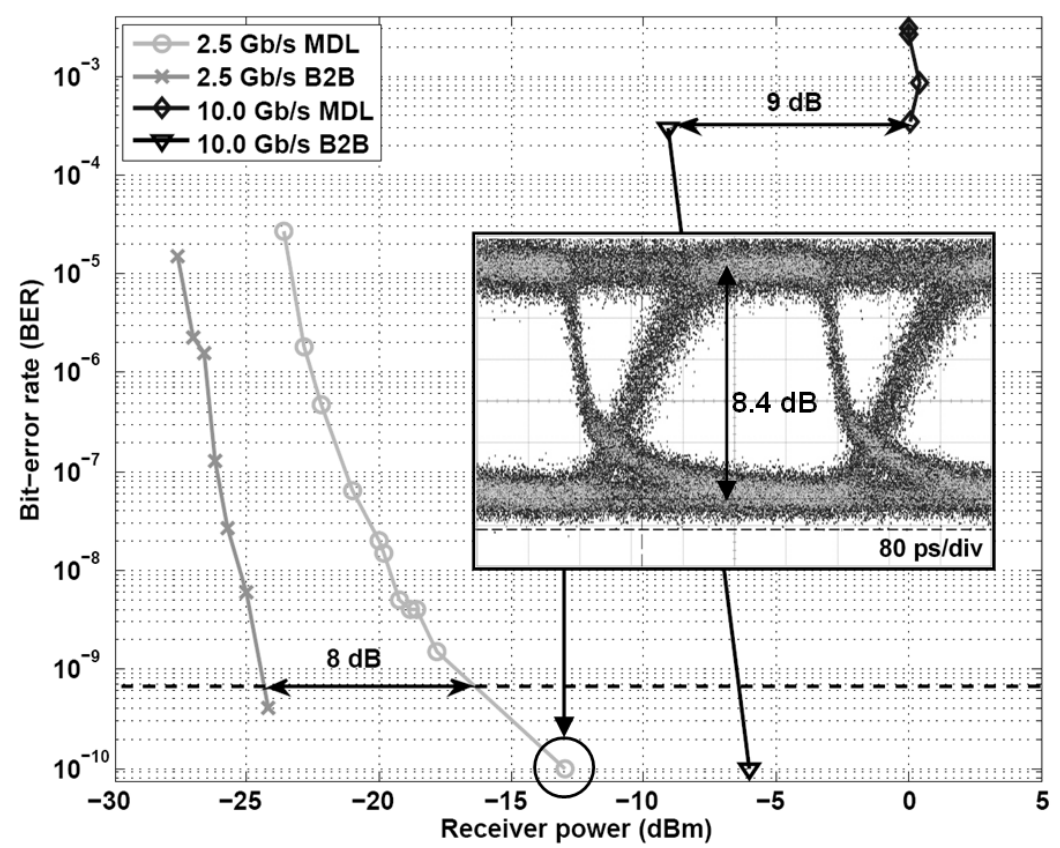

